\title{
A PESQUISA COM OS LIVROS COLETÂNEAS E O ENSINO DE SOCIOLOGIA NA EDUCAÇÃO BÁSICA: PERCURSOS E EXPERIÊNCIAS ${ }^{1}$
}

\author{
Lígia Wilhelms Eras $^{2}$
}

- Enviado em 18/09/2015

- Aprovado em 01/11/2015

\section{RESUMO}

$\mathrm{O}$ artigo em destaque descreve o percurso e as modalidades de pesquisa e a densa experiência, desafios e as justificativas de se empregar os esforços de reflexão em cujo objeto prioritário da investigação incidiu sobre as condições da produção dos livros coletâneas sobre o ensino de sociologia na educação básica materializados para o espaço e o formato de livros coletâneas.

Palavras-chave: Ensino de Sociologia. Livros Coletâneas. Metodologias de pesquisa. Trajetórias.

\section{INTRODUÇÃO}

A pesquisa exposta analisou o processo de produção do conhecimento a respeito do Ensino de Sociologia/Ciências Sociais na Educação Básica no Brasil, mais especificamente no que se refere ao formato de livros coletâneas. A proposta explorou por uma análise crítica dos conteúdos acerca das condições de produção e da trajetória sociohistórica desse conhecimento. Considera-se, portanto, a temática das obras, seus agentes produtores e as tensões contidas na explanação de ideias no debate entre a escola e a universidade. Para atender a abordagem quanto ao formato de livros coletâneas, há o recorte temporal de 2008-2013, onde estão localizadas, de forma densa, as

1 ERAS, Lígia Wilhelms. A produção de conhecimento recente sobre o Ensino de Sociologia/Ciências Sociais na Educação Básica no formato de livros coletâneas (2008-2013) Sociologias e Trajetórias. Programa de Pós-Graduação em Sociologia. Universidade Federal do Paraná. Tese de doutorado defendida em 30/05/2014. Orientação: Prof. Dr. Ricardo Costa de Oliveira (UFPR). Versão completa disponível na Biblioteca Digital da UFPR: http://dspace.c3sl.ufpr.br:8080/dspace/handle/1884/36082.

2 Graduada em Ciências Sociais pela Universidade Estadual do Oeste do Paraná (UNIOESTE). Licenciada em Sociologia pela Universidade Tecnológica Federal do Paraná (UTFPR). Mestre em Linguagem e Sociedade pela Universidade Estadual do Oeste do Paraná (UNIOESTE). Doutora em Sociologia pela Universidade Federal do Paraná (UFPR). Endereço eletrônico: ligiaweras@ hotmail.com 
produções bibliográficas da área. O tema de pesquisa vinculou-se aos estudos do Ensino de Sociologia/Ciências Sociais. Assim, o objeto da análise refletiu sobre a condição da produção bibliográfica recente sobre o Ensino de Ciências/Sociais no formato de livros coletâneas.

A questão a que se propõe a problemática da pesquisa incide à dinâmica dessa produção em torno dos livros coletâneas, na qual se pretende inferir - Como o ensino de Sociologia na Educação Básica é analisado no debate acadêmico das Ciências Sociais e o que essa produção bibliográfica em livros coletâneas revela sobre esse campo de estudos?

A análise do debate de produção bibliográfica destaca as influências das leituras de "A Vocação das Ciências Sociais no Brasil: um estudo da produção em livros do acervo da Biblioteca Nacional 1945 a 1966", de Glaucia Villas Boas em (2007) e "Antropólogos Brasileiros e Antropologia no Brasil: a era da pós-graduação" de Christina de Rezende de Rubim (1996).

Villas Boas (2007), realiza a análise sociológica em torno da produção de livros em Ciências Sociais no Brasil, no qual priorizava a bibliografia como instrumento de abordagem. Contudo, a autora menciona que a falta de ênfase à metodologia pode esvaziar o sentido do patrimônio materializado em pesquisas como índice de institucionalização do conhecimento científico. De acordo com Villas Boas, as possíveis consequências do descaso do uso da bibliografia acumulada é a efetiva falta de informação sobre livros e revistas que poderiam conferir organicidade às discussões. Desse modo, limita-se o diálogo a um único cânone interpretativo. Em outras palavras, o desconhecimento sobre a produção bibliográfica cria uma barreira significativa para os avanços na área, tendo-se recorrentemente como diz a máxima, "inventar a pólvora". Ao enfatizar o lugar e a valorização da memória das Ciências Sociais, a autora consegue, em sua tese, relacionar as obras elencadas a distintos projetos de desenvolvimento brasileiro. Observa, para tanto, o gradativo processo de autonomia do campo, na medida em que começa a se desligar das ponderações políticas. A saber, quando se pergunta "de que maneira a experiência social e histórica são marcantes no período de 1945-1966 e se traduzem na divulgação e produção de conhecimento nas Ciências Sociais", Villas Boas expõe uma sistematização rara dos livros em Ciências Sociais, pelo sentido amplo a partir de diversas áreas e seus respectivos temas.

Assim, ao prefaciar sua obra, José Murilo de Carvalho (2007), destacava a importância da pesquisa para desafiar os cânones da produção em Ciências Sociais. A intenção é para que se visualizem perspectivas de desenvolvimento de pesquisas; incorpore-se à prática sociológica para questionar a história das Ciências Sociais, suscitando o diálogo entre as diversas linhas de pesquisa da sociologia do conhecimento. Ressalta-se que, outro aspecto dessa análise está no fato de que a autora pertence ao campo da produção que analisa relevantes condições históricas. 
Todavia, a discussão de Christina Rezende de Rubim, em sua tese de Doutorado sobre a trajetória do campo da Antropologia no Brasil, também apresentou a constituição do "lugar da memória" pelo histórico da produção das Ciências Sociais, e, de modo mais particular, da Antropologia. A relação suscitada entre ciência, vivência e experiência antropológica revista nesta pesquisa, nos levaram também a pensar a importância em associar a formação de professores e a produção de conhecimento gerada entre o letramento científico e o escolar; além de considerar a transposição da produção científica para a produção escolar.

Para Rubim, analisar a produção bibliográfica, revela quem somos e, a partir desse pressuposto, inferir "como a crítica sobre nós mesmos é uma atitude científica necessária à própria ciência”. Portanto, pela produção da análise acerca da condição bibliográfica sobre o Ensino de Ciências Sociais/Sociologia na Educação Básica é possível perceber que as marcas da intermitência são destaque às sistematizações na área do Ensino de Sociologia Escolar; bem como, da sua militância revela-se a dificuldade na consolidação deste campo de pesquisa. Sobretudo, o lugar fragilizado da Sociologia no Ensino Médio conduziu a temática a se inserir no campo acadêmico e nos cursos de Ciências Sociais sob uma lógica subalterna e um subcampo de pouco interesse aos docentes de titulações e/ou com carreiras mais ligadas à pesquisa; os quais detêm no ensino superior e nos órgãos de fomento, o prestígio e a prática de maior reconhecimento acadêmico (SILVA: 2006; GUELFI, 2006). Há de se considerar que, a Educação esteve localizada em lugares menos privilegiados do campo acadêmico, distinguindo-se, por exemplo, da História das Ideias ou da Sociologia dos Intelectuais - esta com maior legitimidade. Os movimentos mais recentes, no entanto, exteriores à academia, acabaram por repercutir nela, de tal modo que, vive-se hoje uma inflexão na qual o Ensino de Sociologia tornou-se objeto de pesquisa no espaço acadêmico.

Logo, a sistematização elaborada se propõe a inovar além da apresentação descritiva e memorial, justo porque, há um segundo momento no qual se valoriza a análise inédita do conjunto da compilação, uma vez que, avaliou a construção do conhecimento sobre o ensino de Sociologia na Educação Básica no Brasil. Além de que, também analisou os impactos de lutas anteriores tanto no campo do Ensino de Sociologia e em sua demanda no espaço das Ciências Sociais. A produção institucional é apresentada neste estudo e, sobretudo, o balanço dos temas que se repetem e os que se inovam no sentido de avaliar projeções e lacunas desse campo.

Não obstante, os livros coletâneas, objeto desta abordagem, são publicações importantes às definições do campo do Ensino de Sociologia/Ciências Sociais pelas quais assumem múltiplos sentidos: a) resultado e síntese na tentativa de democratizar o acesso às discussões provenientes de eventos, grupos de trabalhos e pesquisas e de experiências teórico-didáticas; b) espaço de 
interlocução entre o campo acadêmico das Ciências Sociais e o campo escolar; c) material de formação, interlocução, subsídio ao trabalho dos professores de Sociologia na Educação Básica em sala de aula; d) espaço de problematização dos temas relativos às novas configurações do campo e redefinições de fronteiras epistemológicas; e) patrimônio imaterial, memorial e registros do trajeto de constituição do conhecimento sociológico escolar; d) espaço privilegiado de circulação das ideias e difusão do conhecimento da sociologia escolar acerca de sua especificidade condicionada à prática do pensamento sobre o ensino, dilemas, alternativas e futuras projeções do campo. É importante considerar que, os livros coletâneas são dispostos e comercializados por editoras do mercado editorial privado e/ou editorados com recursos públicos, frutos de projetos de fomento à formação de professores e/ou vinculados às editoras das universidades públicas e/ou federais.

Ademais, o recorte temporal que concedeu suporte à pesquisa é peculiar para visualizar o aumento das produções, que preservam, quase em sua totalidade a produção da área e o sentido da coletividade - marcas de seu habitus e deste campo - na organização das obras, no estabelecimento das autorias e no destino dos livros coletâneas e na propagação de diferentes ideias coletivas: os licenciados e licenciandos em Ciências Sociais; os professores de Sociologia na Educação Básica; os estudantes de Ensino Médio; os professores pesquisadores sobre os temas relacionados ao Ensino de Ciências Sociais/Sociologia, os pares professores de disciplinas ligadas à formação de professores de Sociologia; os cursos de Ciências Sociais; os diferentes espaços de diálogo com diferentes áreas das Ciências Humanas e o campo do conhecimento dos saberes docentes e educacionais.

Neste contexto, elaborei a sistematização que contém 27 (vinte e sete) livros coletâneas ${ }^{3}$, específicos sobre o Ensino de Sociologia na Educação Básica (2004 a 2013), os quais reúnem cerca

3 BRIDI, Maria Aparecida; ARAÚJO, Sílvia Maria; MOTIM, Benilde Lenzi. Ensinar e aprender Sociologia. São Paulo: Contexto, 2010; CAINELLI, Marlene Rosa; SILVA, Ileizi Fiorelli (org.). O estágio na licenciatura: a formação de professores e a experiência interdisciplinar na Universidade Estadual de Londrina. Londrina: UEL, 2009; CARVALHO, Cesar Augusto (org.). A Sociologia no Ensino Médio (org.) - Londrina: EDUEL, 2010; CARVALHO, Lejeune Mato Grosso (org.). Sociologia e ensino em debate: experiências e discussão de sociologia no ensino médio. Ijuí: Ed. Unijuí, 2004; COLOGNESE, Silvio Antônio (org.). Fronteiras do saber sociológico. Porto Alegre: Evangraf, 2012 ; Novas fronteiras para o saber sociológico. Porto Alegre: Evangraf, 2013; FIGUEIRO, André Videira; OLIVEIRA, Luiz Fernandes; PINTO, Nalayane Mendonça (orgs.). Sociologia na sala de aula: reflexões e experiências docentes no Estado do Rio de Janeiro. Rio de Janeiro: Imperial Novo Milênio, 2012; FERREIRA, Lúcia de Fátima Guerra (org.). Subsídios para a educação em direitos humanos nas ciências sociais. João Pessoa: Editora Universidade da UFPB, 2010. GONÇALVES, Danyelle Nilin (org.). Sociologia e Juventude no Ensino Médio: formação, PIBID e outras experiências. Pontes Editores: Campinas, 2013; HANDFAS, Anita. OLIVEIRA, Luiz Fernandes (orgs.). A Sociologia vai à escola - Rio de Janeiro: Quartet FAPERJ, 2009; HANDFAS, Anita; MAÇAIRA, Júlia Polessa (orgs.). Dilemas e perspectivas da Sociologia na Educação Básica. Rio de Janeiro: E-papers: 2012; LIMA, Ângela Maria de Sousa (org.) As persistentes desigualdades brasileiras como temas para o Ensino Médio. Londrina: Eduel, 2011; LIMA, Angela Maria de Sousa; ARAÚJO, Angélica Lyra; FERREIRA, Jaqueline; MOTTA, Sílvia Conceição Longuin (orgs.). Sugestões didáticas de Ensino de Sociologia. Londrina: UEL, 2012; LIMA, Angela Maria Sousa, VITALIANO, Célia Regina, ALTIANO, Fabiane Cristina, MACHADO, Rosemeri Passos Baltazar (orgs). Inclusão: debates em diferentes contextos. Londrina: EDUEL, 2013; LIMA, Angela Maria Sousa, ARAÚJO, 
de 550 (quinhentos e cinquenta) capítulos. Embora se saiba que também há outros livros produzidos por cursos de Licenciatura e/ou Bacharelado em Ciências Sociais, que apresentam temas correlatos ao espaço educacional e uma grande leva de novas publicações que serão editorados e lançados ao público, apenas se menciona neste exposto, a descrição dos livros que apresentam discussões mais exclusivas às relações de Ensino e Sociologia Escolar.

Contudo, o período de recorte deste enfoque, considera apenas a análise dos livros lançados entre os anos de 2008 a 2013, onde está concentrado o aumento da produção, no formato previamente descritivo e, que, a posteriori, demonstrou nossas ideias e posicionamentos em face das publicações. A proposta abrange o debate que se materializa na constituição das obras e demonstra o impacto dessa discussão pelo espaço de produção e de reconhecimento sobre o Ensino de Sociologia/Ciências Sociais na Educação Básica no campo das Ciências Sociais.

Além disso, está especificada de acordo com a produção simbólica de cada ato coletivo e seus momentos mais marcantes, como os que seguem: I. a reflexão sobre a campanha do retorno do ensino de Sociologia na Educação Básica; II. a reflexão sobre o sentido do veto presidencial de Fernando Henrique Cardoso $(2001)^{4}$; III. as reflexões em torno da obrigatoriedade do ensino, a partir da Lei $n^{\circ} 11.684$, de 02 de junho de 2008; IV. a reflexão sobre o programa nacional dos conteúdos sobre o ensino de sociologia; V. a avaliação crítica da presença do Programa Institucional de Bolsas de Iniciação a Docência (CAPES/PIBID). Enfim, a cada rodada de debates, à distinção nas relações de ensino na formação de professores e na Educação Básica, que confere à

Angélica Lyra; LIMA, Alexandre Jerônimo Correia; FERREIRA, Adriana Fátima; CARVALHO, Cézar Augusto; SILVA, Ileizi Luciana Fiorelli; SCHEVIBISKI, Renata Schlumberger; SILVEIRA, Ricardo de Jesus (orgs.). Práticas e Debates na formação de professores de Sociologia/Ciências Sociais. Londrina: EDUEL, 2013; MEIRELLES, Mauro; RAIZER, Leandro; PEREIRA, Luiza Helena (orgs). O ensino de sociologia no RS: repensando o lugar da sociologia. Porto Alegre: Evangraf/LAVIECS, 2013; MORAES, Amaury César (org.). Coleção Explorando o Ensino. Sociologia. Volume 15. Ministério da Educação, Secretaria de Educação Básica, 2010; OLIVEIRA, Dijaci David; RABELO, Danilo; FREITAS, Revalino Antônio (orgs). Sociologia no Ensino Médio: experiências e desafios. Goiânia: UFC/FUNAPE, 2010; Ensino de Sociologia: currículo, metodologia e formação de professores. Goiânia: UFG/FUNAPE, 2011 OLIVEIRA, Dijaci David; FREITAS, Revalino Antônio; TOSTA, Tânia Ludmila Dias (orgs.). Sociologia e Educação em direitos humanos. Goiânia: UFG/FUNAPE, 2010; OLIVEIRA, Luiz Fernandes, André Videira, Nalayane Pinto (orgs). Sociologia na sala de aula: reflexões e experiências docentes no Estado do Rio de Janeiro. Rio de Janeiro: Imperial Novo Milênio, 2012; OLIVEIRA, Luiz Fernandes (org.). Ensino de Sociologia: desafios teóricos e pedagógicos para a s Ciências Sociais. Seropédica-RJ: Editora da UFRRJ, 2013; OLIVEIRA, Márcio de (org.). As Ciências Sociais no Paraná. Curitiba: Protexto, 2006; PLANCHEREL, Alice Anabuki. OLIVEIRA, Evelina Antunes F. (orgs.) Leituras sobre sociologia no Ensino Médio. Maceió: EDUFAL, 2007; RAMALHO, José Rodorval. SOUZA, Rozenval de Almeida (org.). Pibid: Memórias de iniciação à docência Campina Grande: Editora da UFCG, 2013; SANTOS, Adriana Regina de Jesus (orgs). Práticas e reflexões de ensino e pesquisa do projeto PRODOCÊNCIA da UEL. Londrina: Universidade Estadual de Londrina, 2012; SILVA, Ileizi Luciana Fiorelli (orgs.) Cadernos de metodologias de ensino e pesquisa de sociologia: Lenpes laboratório de ensino, pesquisa e extensão de sociologia. Curitiba: SETI-PR, 2009; SOUSA, Fernando Ponte (org.). Sociologia conhecimento e ensino. Florianópolis: Editora em Debate, 2012.

4 Veto ao Projeto de Lei 09/2000, aprovado no Congresso Nacional que estabelecia o retorno de Filosofia e Sociologia no Ensino Médio. 
produção novos sentidos ao campo à medida que avança a sua capacidade de se auto-refletir a Sociologia das Conflituosidades neles contidos como habitus.

As ações anteriormente destacadas, resultam em uma produção bibliográfica crescente, que não mais pode ser subestimada e, que é nesta tese está elaborada para evidenciar a potencialidade das novas pesquisas no desenho das licenciaturas, de um lado, quiçá também dos bacharelados.

Logo, a justificativa desta pesquisa atendeu a necessidade de registrar, analisar e diagnosticar a história que ainda está sendo produzida nas instituições escolares e no ensino superior público. Os pressupostos especificamente, consideraram a produção bibliográfica dos livros coletâneas para compreender a linguagem, os inúmeros capítulos e o discurso contido para além do seu formato material físico. Os resultados dessa pesquisa de ordem científica auxiliarão a compreensão desse campo de estudos. Assim, os dados projetados darão suporte à produção de novas pesquisas.

A explanação da abordagem considera os seguintes objetivos: a) sistematizar o conjunto da produção bibliográfica no formato de livros coletâneas no Brasil na forma de análise de conteúdos sobre as contribuições ao campo de estudos; b) analisar a construção social, cultural, autoral e institucional como condição de inserção das obras no circuito da circulação das ideias; c) observar como é retratada a formação do professor de Sociologia e suas políticas públicas.

O debate exposto sistematiza a base de ideias que comporta o campo das Ciências Sociais, uma vez que, é uma necessidade inerente à atividade do cientista social pensar a sociedade de modo constante. No Ensino de Ciências Sociais/Sociologia na Educação Básica, há várias tentativas de sistematização de ideias, porém com recortes e, por sua vez, não são abrangentes quanto à historicidade das Ciências Sociais.

O campo da produção bibliográfica sobre o Ensino de Ciências Sociais/Sociologia na Educação básica é permeado de interação acadêmica, tanto que, é possível perceber a luta pela posse do capital. A produção acontece em busca da legitimidade do ensino, via relações jurídicas do Estado do qual decorriam também os debates teórico-epistemológicos. Além disso, dos embates pragmático-políticos derivam avaliações de experiências e produção de diagnósticos, elaboração de novos materiais didáticos, práticas e metodologias de ensino, dentre outros. Tratava-se de respaldar a crença na importância da Sociologia na formação dos jovens (Sociologia na Educação Básica, Sociologia da Juventude). A rigor, pretende-se pelo material pedagógico e didático a reorganização das Licenciaturas em suas disciplinas basilares (Fundamentos Teórico-Metodológicos; Epistemologias de Ensino; Teorização das Práticas/Reflexão crítica teorizada das transposições didáticas; Legislação Educacional da Educação Básica ao Ensino Superior; Reflexão da 
Historicidade das práticas, metodologias e cursos). Neste período, surgem as oficinas ou os laboratórios de estágios como instâncias de amadurecimento dos processos de produção sociológica e vivência escolar. Neste contexto, constitui-se um campo de debates do qual participam agentes políticos, agentes estatais (como as burocracias educacionais, por exemplo), agentes da Educação Básica e Ensino Superior.

\section{O PERCURSO METODOLÓGICO: ENTRE OPÇÕES TEÓRICO-METODOLÓGICAS}

Ao detalhar de modo preciso o processo de constituição dessa pesquisa, posso afirmar que o percurso metodológico se pauta na diversidade da minha trajetória de formação acadêmica e profissional - no campo de estudos sobre o Ensino de Sociologia/Ciências Sociais na Educação Básica. A propósito, a atuação profissional que vivenciei, perpassou por inúmeras vezes o espaço das Licenciaturas, e de modo especial, pela Licenciatura em Ciências Sociais ${ }^{5}$ e seus desafios simbólicos e epistemológicos para a formação docente. Portanto, a inquietação teve por alicerce as duas formações: do cientista social para a educação e da educação para o cientista social.

A participação em vários eventos da área proporcionou-me um contato direto e frequente nas diversas modulações temporais e reflexivas do campo, em congressos, seminários, simpósios regionais, estaduais e nacionais do tema. A oportunidade de conhecer a realidade em várias perspectivas de pesquisas e de ensino, desencadeou em ganho analítico sobre as discussões culturais do grupo, bem porque, possibilitou o acesso aos dados de dimensões históricas, simbólicas, culturais e políticas que configuram a expressão do cientista social nesse campo.

No entanto, quando se revela ao público leitor as opções metodológicas de uma pesquisa, é mais do que esclarecer posicionamentos e procedimentos ético-científicos. O compromisso maior está, sobretudo, naquilo que esse percurso e na produção desta tese, possa, de fato, gerar superação. Portanto, a proposição temática não é um mero conhecimento da produção, do seu sentido epistemológico-teórico, mas é, a efetiva necessidade de compreender a realidade e nela poder intervir. Para tanto, utilizaram-se três metodologias de pesquisa e inúmeros instrumentos para coleta e acesso aos dados, mediante a complexidade desta pesquisa:

1. Metodologia e problematização histórica (levantamento histórico-bibliográfico sobre o tema, acervo de documentos, eventos acadêmico-científicos, relatos sobre o processo de

5 Professora Colaboradora do Curso de Licenciatura em Ciências Sociais da Universidade Estadual do Oeste do Paraná - Unioeste. 
mobilização/campanha pelo retorno do Ensino de Sociologia no Ensino Médio), documentos legislativos relacionados à esfera educacional recente: Lei de Diretrizes e Bases - LDB; Diretrizes Curriculares Nacionais - DCN's; Parâmetros Curriculares Nacionais - PCN's. A metodologia aqui é de natureza histórico-cronológica-sociológica qualitativa.

2. Metodologia prosopográfica da biografia coletiva dos autores de textos dos livros coletâneas priorizando a análise de trajetória sociopessoais, profissionais, formação escolar e acadêmica e de produção bibliográfica (instrumentos diversificados/complementares para a coleta dos dados: produção bibliográfica com informações biográficas; uso do curriculum lattes no acesso à Plataforma de dados do CNPq; aplicação de um roteiro de pesquisa on-line e sistematização dos fatores comuns de resposta e a perspectiva de aproximação e diferenciação das respostas). A metodologia desenvolvida é de natureza quantitativa e qualitativa;

3. Metodologia de análise de conteúdos temáticos (perspectiva crítico-sociológica) dos livros coletâneas produzidos no período de 2008 a 2013, em três dimensões/categorizações de análise: a linguagem, os temários e a construção das agendas temáticas do campo (procedimentos de categorização, descrição e interpretação/análise das obras). A metodologia de apoio é de natureza qualitativa.

\subsection{Metodologia e problematização histórica}

Sabe-se que, o traço histórico é importante ao entendimento da dinâmica de construção do campo sobre o Ensino de Sociologia/Ciências Sociais. Este fato perpassa por múltiplas tensões no seu curso temporal, em modulações de historicidades compostas pelas primeiras aparições da disciplina de Sociologia nos cursos secundários e, posteriormente, durante a década de 20 a 30, a institucionalização dos conhecimentos ligados às Ciências Sociais no Brasil e os seus principais fundamentos teóricos e metodológicos.

A perspectiva histórica $^{6}$ utilizada nessa pesquisa atendeu a um mapeamento sociocronológico e de uma análise sociológica e analítica de cada uma das modulações de processo histórico da trajetória da História do Ensino de Sociologia/Ciências Sociais na Educação Básica. Além disso, houve a intenção de interpretar criticamente a identificação das determinações sociais, políticas, culturais e educacionais que atravessam o ensino. O traço da intermitência é uma identidade significativa de tempo que demarca esse campo e que o move numa atitude constante de

6 Vide: BURKE, Peter (org.). A escrita da história. São Paulo: Unesp, 1992; HOBSBAWM, Eric J. Sobre História: ensaios. SP: Cia das Letras, 1998; KOSELLECK, Reinhart. Futuro passado: contribuição à semântica dos tempos históricos. Rio de Janeiro: Contraponto/PUC, 2006. 
luta pela sua afirmação na esfera da Educação Básica, onde historicamente os seus dilemas foram/são manifestos, como as campanhas pelo seu retorno, que para além da busca de uma legitimidade, também estão inscritas no percurso histórico recente; e, de seus efeitos nas ações legislativas educacionais contemporâneas, o movimento também historicamente busca legitimar o conhecimento sociológico e/ou das Ciências Sociais no seu sentido epistemológico e didático, em que possa circular e ser reconhecido no espaço de discussões no interior das Ciências Sociais e na escola. Nosso objeto de estudo, os livros coletâneas, transitam nesse debate a partir de todo o arsenal histórico cujas ideias sociológicas e educacionais foram e ainda são travadas.

Entretanto, para atender ao objetivo, utilizou-se de diferentes recursos de reconstituição e identificação de como essas diferentes modulações históricas se processaram, avaliadas com relação ao objeto de estudos - os livros coletâneas - sempre numa orientação processual e relacional que se entrecruzam, reconstituídas por trabalhos de levantamento histórico-bibliográfico sobre os temas, especialmente os contidos nos próprios livros coletâneas em análise - acervos de documentos e eventos acadêmicos científicos da área, além do relato de vários agentes sobre o processo de constituição da campanha de retorno da disciplina nas escolas e os trâmites e os reflexos desses processos na análise dos estudos sobre a legislação educacional recente e de uma história - da sociologia e da educação - que ainda não se encerra, mas segue novos rumos.

\subsection{Metodologia prosopográfica da biografia coletiva dos autores}

À medida que acompanhava o debate como estudiosa do assunto, compilei e organizei a extensão da produção bibliográfica disseminada em nosso país, no período de 1993 a 2013. Deste modo, um dado expressivo chamou minha atenção - o volume deste acervo. A produção cresceu muito, e de modo mais singular, nos últimos cinco anos, numa relação direta com a inscrição do Ensino de Sociologia na Educação Básica, pela via legal. Nessa identificação, observou-se que, os espaços de produção se diversificavam, a produção começava a aparecer na pós-graduação, em eventos acadêmicos, em eventos de organizações corporativas dos sociólogos, em revistas, em documentos encomendados aos agentes presentes nas universidades pelos órgãos oficiais (MEC e SEED’s) e em livros didáticos e inúmeras outras produções.

A atenção se explica no fato que, um dos espaços em que se fomentam as reflexões sobre o Ensino de Sociologia, está nos cursos de Licenciatura, especialmente onde estão os professores de Metodologia de Ensino e outros agentes do Ensino Médio. Diante disso, realizei concomitantemente ao levantamento bibliográfico, um levantamento quantitativo, que permitisse facilmente mapear o 
número e a localização dos cursos de Licenciatura em Ciências Sociais do país. Para isso, foi utilizada como fonte de consulta o acesso aos dados da Plataforma de dados do Ministério de Educação (E-MEC). Essa compilação demonstrou que as Licenciaturas cresceram na oferta do setor público e privado do ensino superior. Sobretudo, o crescimento dos cursos e o volume da produção bibliográfica anunciam os lugares de produção e circulação no ensino.

Ademais, como a totalidade da produção é extensa, em minhas orientações de pesquisa, fui aconselhada a projetar um recorte significativo sobre essa produção, o que fez que a pesquisa atentasse à dinâmica da produção dos livros coletâneas; justo porque, é um objeto ainda não abordado nesse campo de estudos. Mas que, também tem uma correlação direta com o Ensino de Sociologia na Educação Básica, como lugar de reflexão sobre o próprio cientista social trabalhando pela educação. Posteriormente, ao primeiro filtro das delimitações do objeto de estudo - a produção bibliográfica dos livros coletâneas - era necessário eleger um método ao tratamento do conjunto de textos e dados coletados.

Não obstante, o livro coletânea é uma ferramenta primordial ao meu ofício no ensino e na pesquisa. Assim, eu possuía um grande acervo de livros coletâneas da área e os incorporei a outros, por aquisição pessoal ou acessado via doações (por serem obras produzidas com recursos públicos voltados para o ensino e a pesquisa). Este material produção se tornou meu objeto de investigação científica. Todavia, haveria lacunas se não fossem observadas as trajetórias dos produtores - os autores dos textos dos livros coletâneas e os sentidos de suas atuações coletivas. Nesse caso, duas ações foram necessárias ao desafio: a) trabalho de campo e coleta de dados; b) análise de trajetória por prosopografia.

Para a primeira etapa, foi preciso elucidar um roteiro de questões on-line para o procedimento de coleta de dados ${ }^{7}$. Essa decisão se sustentou pela busca de um meio que coadunasse o alcance dos autores dos livros coletâneas; para tanto, foi preciso considerar as distâncias geográficas e institucionais e um conjunto amplo de informações necessárias à compreensão das trajetórias sociopessoais, profissionais, de formação acadêmica e de produção bibliográfica. Elaborei um roteiro com questões semi-estruturadas abertas e fechadas, que permitissem fácil preenchimento. Apesar de ser extenso, precisaria levar os autores a contribuir com a pesquisa. Assim, anexo a esse exercício, também foi remetida uma apresentação da pesquisa e um termo de consentimento livre e esclarecido, que reafirmasse meu compromisso ético e científico na condução dessa proposta de pesquisa. No entanto, no processo de levantamento das autorias dos livros

$7 \mathrm{O}$ roteiro foi enviado no mês de dezembro/2013 e, sequencialmente, respondido durante o período de dezembro/2013 a fevereiro/2014. 
coletâneas, que participassem mais assiduamente e quantitativamente do debate, 20 (vinte) nomes persistiam no debate. Em um novo recorte (a partir da representatividade institucional e regional do debate), enviei 18 (dezoito) roteiros via e-mails. Houve o retorno de 15 (quinze) questionários respondidos, correspondendo ao recorte da proporcionalidade de $83,33 \%{ }^{8}$.

A cultura colaborativa do grupo, o amplo acesso aos contatos e endereços eletrônicos, bem como, a participação em diversas dinâmicas e momentos de estudos fizeram com que se alcançasse êxito na tarefa. $\mathrm{O}$ volume dos dados coletados revela o engajamento da área e o interesse dos agentes pela ampliação do campo de estudos e do aumento de perspectivas de pesquisas sobre o tema. Uma sociologia da sociologia do Ensino de Sociologia surge como proposta importante para um momento de avaliação do pós-inclusão do ensino de Sociologia na Educação Básica; uma vez que intenciona a ampliação de espaços de produção de livros, laboratórios, revistas e de políticas públicas de fomento a formação docente em franca expansão. Porém, é preciso avaliar além dos avanços, o gerenciamento de inovações a serem ainda conquistadas por essa linha de estudos.

O que também nos levou a prosseguir utilizando canais informacionais como instrumento de coleta de dados para essa pesquisa, foi o contato com um conjunto de leituras de autores como Ronaldo Baltar e Claudia Baltar ${ }^{9}$, Tom Dwyer ${ }^{10}$ e José Vicente Tavares dos Santos ${ }^{11}$, cada um a sua maneira, apresentam renovado cenário problemático, que convoca as Ciências Sociais a uma convivência mais interativa no "uso de informação aplicada ao Ensino e a Pesquisa em Ciências Sociais" e de construção de conhecimentos intermediados por tais interfaces somados à devida formação e adequação sistêmica, teórica, analítica, interpretativa de análise desses dados para a dinamização da área das Ciências Sociais. De certa maneira, a própria formação do cientista social é inquirida nos cursos de graduação e pós-graduação à tarefa associada ao seu métier. Logo, no universo amplamente intermediado pelo uso das tecnologias, era inevitável a necessidade de compor, criticamente essa metodologia, associada a um roteiro de questões que pudessem auxiliar o entendimento sobre o campo.

\footnotetext{
8 Apenas três questionários não retornaram, e ainda assim, com retorno de justificativas, em função de problemas de saúde na família e/ou outros problemas de força maior que impediram que pudessem participar com suas respectivas informações, no tempo estipulado para a coleta dos dados.
}

9 BALTAR, R.; BALTAR, C. S. A defasagem das ciências sociais no uso de recursos de informática para o ensino e a pesquisa no Brasil. La Educación - Revista Digital (OEA), v. 144, p. 2, 2010.

10 DWYER, Tom. As tecnologias de informação: morte ou vida para as ciências humanas? Sociologias, Porto Alegre, n. 12, Dec. 2004.

11 SANTOS, José Vicente Tavares dos. As Metodologias Informacionais: um novo padrão de trabalho científico para as Sociologias do Século XXI?. Sociologias. Porto Alegre, n.5, June 2001. 
A segunda etapa da organização, foi sistematizar os dados num agrupamento por aproximações e diferenciações de respostas a partir de um quadro de quatro análises da composição de uma proposografia de grupo: trajetória sociopessoal, profissional, formação escolar e acadêmica e produção bibliográfica; esse método foi esclarecido pelo orientador da pesquisa, o qual sugeriu a leitura de pesquisas ${ }^{12}$ em que pudesse visualizar esse exercício, considerando os ajustes particulares à discussão que movia em torno do Ensino de Sociologia. $\mathrm{O}$ empreendimento foi significativo à pesquisa e, isso é apontado pelo próprio Lawrence Stone (2011), pioneiro no uso do método, principalmente nos estudos ligados à Sociologia Política, de que nem sempre é alcançável, uma extensão completa de dados (em nosso caso, a não exploração da genealogia dos agentes, uma vez que, isso não determinaria um entendimento geracional). Pode-se apreender as noções de origem familiar e, especialmente do lugar central da educação em suas trajetórias, como algo a ser duramente conquistado e não garantido por uma situação de herança cultural ou genealogia familiar. A originalidade dessas discussões permite a melhor compreensão de quem são os autores, de que lugares falam e qual tomada de partido há onde são participantes.

A complementação dessa metodologia se deu também pelo uso de informes biográficoinstitucionais, apresentados durante a composição dos capítulos dos livros e, por sugestão dos próprios agentes entrevistados, ao buscar algumas informações mais extensas, como a da sessão da produção bibliográfica, no acesso e do uso da Plataforma de dados do curriculum lattes, disposto no sítio eletrônico do CNPq. Há uma tendência cada vez maior, na utilização do curriculum lattes como ferramenta de pesquisa, especialmente problematizados pelos profissionais da ciência da informação ${ }^{13}$, que buscam inovar novos sistemas de apreensão e cruzamento desses dados, dinamização no acesso, divulgação e acesso a resultados de pesquisa e localização de pesquisadores. Reitera-se que, o uso desse instrumento de pesquisa, foi especialmente utilizado, na verificação da produção bibliográfica e migrações institucionais dos agentes interrogados nesse estudo.

12 Vide: OLIVEIRA, Ricardo Costa. A Universidade que a genealogia paranaense criou em 1912. In: LEITE, Renato Lopes; OLIVEIRA, Ricardo Costa. Reflexões UFPR 100 anos. Curitiba: Editora UFPR, 2012; OLIVEIRA, Ricardo Costa. Na teia do nepotismo: Sociologia Política das relações de parentesco e poder político no Paraná e no Brasil. Curitiba: Insigth, 2012; PULICI, Carolina. Entre sociólogos: versões conflitivas da "condição de sociólogo" da USP dos anos 1950-1960. São Paulo: Editorada Universidade de São Paulo/Fapesp, 2008; SPIRANDELLI, Claudinei Carlos.Trajetórias intelectuais: professores do Curso de Ciências Sociais da FFCL-USP (1934-1969). Tese de Doutorado em Sociologia. São Paulo: Universidade de São Paulo (USP), 2008.

13 Vide: FARIAS, L; VARGAS, A; BORGES, E. Um sistema para análise de redes de pesquisas baseado na plataforma Lattes. Revista Eletrônica de Sistemas da informação. Volume 10, 2006. Disponível em http://paginas.ucpel.tche.br. Acesso em abril de 2014; NUNES, Patrícia. Alfabetização científico-tecnológico-digital e a Plataforma Lattes: quais sentidos? Dissertação de Mestrado em Educação. Programa de Pós-Graduação de Educação. São Leopoldo-RS: UNISINOS, 2006. 


\subsection{Metodologia de análise de conteúdos temáticos}

A pesquisa se propôs a desenvolver a sistematização da produção desse debate em torno da circulação das ideias sobre o Ensino de Ciências Sociais/Sociologia na Educação Básica no Brasil. Nesta abordagem, há o levantamento bibliográfico, a seleção e a análise de conteúdos das produções dos livros coletânea, na perspectiva de avaliação do estado da arte sobre essa produção. Para tanto, os dados empíricos são apresentados em três orientações: I) A primeira delas é uma descrição que possibilite ao leitor, percorrer o debate e as diferentes fases de constituição do campo e do conhecimento das Ciências Sociais/Sociologia escolar "aos seus olhos"; II) um segundo momento, ponderou-se a elaboração de uma demonstração reflexivo-crítica em face das ideias apresentadas durante a produção; III) terceiro e último, apresentou-se ao público leitor a sistematização das tipologias de conhecimento, geradas a partir do contato com o debate e o seu grau de intervenção na aproximação entre o pensamento e as relações de ensino nas Ciências Sociais; IV) a incursão desse debate, a nível nacional o que permitirá elucidar um painel quanto à sua criticidade, num filigrama dos diferentes temas e abordagens que aparecem no debate sobre o Ensino de Ciências Sociais/Sociologia, bem como os que desaparecem, por alguma razão, dessa discussão.

Sobretudo, como se mencionou, o processo de contextualização foi fundamental à composição da pesquisa, seja pelo seu contexto histórico-temporal, seja pelo contexto legal, seja pelo contexto de produção autoral, ou seja, ainda, pelo contexto das obras produzidas (quem fala (autorias), o que fala (mensagem), a quem fala (recepção e circulação das ideias), de que modo falam (produção e linguagem sociológica e escrita), com que finalidade falam (objetivos) e que resultados produzem (que linguagem e discurso perito e epistemologias geram). $\mathrm{O}$ trabalho desenvolvido arquitetou-se em dois movimentos:

a) apreensão e especificidades da área e identificação das respectivas agendas e discussões temáticas, num processo de codificação das amostras, da unitarização das análises (significado dos registros ao campo), categorizações temáticas no agrupamento dos textos/dados, em uma análise processual, crítica, relacional e contextual dos conteúdos; além da interpretação que supera a descrição (que também compõe um momento de realização da pesquisa, ao descrever as obras, os assuntos e os contextos ao público leitor deste trabalho). Sendo assim, houve no exercício de compreensão dos conteúdos e significados, teorização na compreensão do fenômeno da dinâmica de produção dos livros coletâneas sobre o Ensino de Sociologia/Ciências Sociais; 
b) a perspectiva da síntese nas análises, na apreensão do conjunto dos resultados, tipologias de conhecimentos elaborados nessas produções, quais Sociologias e sentidos estão implícitos nesses projetos e programas de produção de conhecimento sobre o Ensino de Sociologia/Ciências Sociais na Educação Básica. O conjunto de demandas e transformações sócio-culturais-políticas, educacionais-informacionais sobre as quais passa a sociedade no contexto do século XXI (conjuntura e mudanças na sociedade; formação das ciências sociais e suas relações com o ensino e a pesquisa).

\section{CONSIDERAÇÕES FINAIS}

Após apresentar os procedimentos de realização desta pesquisa, por meio da análise reflexiva do percurso metodológico, apresentamos ainda as expectativas de leitura e a organização sumariada deste trabalho, por meio de capítulos.

O debate promovido no primeiro capítulo, conforme se mencionou no percurso metodológico, é o de uma análise sociohistórica que demonstra o cenário da trajetória da História do Ensino de Sociologia/Ciências Sociais no locus da Educação Básica. O espaço passa a ser um local de disputa à possível atuação do cientista social - que ora é conquistado e ora é deslegitimado - tanto no campo escolar quanto no campo acadêmico, em diferentes modulações históricas.

No entanto, o movimento de tensão continua para além da situação de indeterminação da Sociologia na escola. Mas, intensifica a dimensão das relações de produção de conhecimento, as quais estão situadas nessa esfera de ensino, que operacionaliza o letramento comunicacional, intelectual, social, cultural, histórico de todo um conjunto sistematizado de saberes em herança geracional (CURY: 2008). Na Educação Básica se instala a compreensão da dinâmica societária, naquilo que ela representa à qualificação para operar direitos e deveres e, sobretudo, experimentar o exercício de cidadania. Logo, é abrangente e se torna ainda mais complexo se considerar as inúmeras variações culturais, de aprendizados, de metodologias e didáticas, enfim, são as infraestruturas que compõem o conjunto das problemáticas instaladas.

No segundo capítulo, dispõe-se um painel de constituição descritiva das produções bibliográficas no formato de livros coletâneas e suas singularidades na construção da produção de conhecimento recente. As distinções em relação ao livro didático e/ou às demais materializações da cultura escrita em relação à escola. Nesse capítulo, estão inclusas as apropriações teóricas dessa pesquisa. Ao dialogar com Pierre Bourdieu, evidencia-se o crivo de um campo em disputa e a 
convocação dos conceitos de campo $^{14}$, habitus $^{15}$, subcampo $^{16}$, capital simbólico $^{17}$ que ajudam a formular uma compreensão sobre o conjunto das relações também presentes e enunciadas no corpus da produção de conhecimento das Ciências Sociais em livros coletâneas. Esses conceitos operam nesse campo de estudo, na composição e ressignificação de ações em que a noção de jogo é rearticulada.

Os estudos de Karl Mannheim ajudam a refletir sobre a visibilidade e o papel da democratização do conhecimento sociológico reivindicado na escola e nas Ciências Sociais. Evidenciam-se os sentidos, as produções e as formações que têm sido proporcionadas às Licenciaturas em Ciências Sociais e a decifrar as linguagens e os discursos peritos e das expertises para diagnosticar a dinâmica da recepção e circulação das ideias. Consideram-se, neste enfoque, os limites no espaço reflexivo, didático e de leitura dos livros, associadas à essas reflexões a compreensão e a formulação de uma comunidade de escrita e de leitores que pelo acesso ao livro coletâneas como limites de superação do seu meio físico, e transferidos para um palco da esfera pública de debate, Roger Chartier subsidia o entendimento da formulação histórica e comunicacional dessas obras.

Para o terceiro capítulo, reservou-se o debate acerca da compreensão das agências e dos agentes produtores de conhecimento no formato de livros coletâneas. Apresenta-se a literatura que influencia a nossa compreensão sobre o método proposopográfico ${ }^{18}$ e identificação da biografia coletiva do grupo. O exercício prosopográfico foi organizado em três processos avaliativos: a) a análise dos traços prosopográficos numa relação central entre o ensino de Sociologia contido na singularidade de cada trajetória autoral; b) na perspectiva de síntese e das configurações da

14 "Em termos analíticos, um campo pode ser definido como uma rede ou uma configuração de relações objetivas entre posições. Essas posições são definidas objetivamente em sua existência e nas determinações que elas impõem aos ocupantes, agentes ou instituições, por sua situação atual e potencial na estrutura da distribuição de diferentes espécies de poder (ou de capital) cuja posse comanda o acesso aos lucros específicos que estão em jogo no campo, e ao mesmo tempo, por sua relações objetivas com outras posições (dominação, subordinação, homologia, etc)" (BOURDIEU, p. $83)$.

15 Um sistema de disposições duráveis e transponíveis que, integradas todos as experiências passadas, funciona a cada momento como uma matriz de percepções, de apreciações e ações - e torna possível a realização de tarefas infinitamente diferenciadas, graças às transferências analógicas de esquemas (BOURDIEU, p. 65, 1998).

16 O subcampo, a partir da teoria bourdieusiana são consideradas regiões menores de um campo, os quais conservam a mesma dinâmica do campo original.

17 “O capital simbólico - outro nome da distinção - não é outra coisa senão o capital, qualquer que seja a sua espécie, quando percebido por um agente dotado de categorias de percepção resultantes da incorporação da estrutura da sua distribuição, quer dizer, quando conhecido e reconhecido como algo de óbvio" (BOURDIEU: 1998, p. 70) 
biografia coletiva do grupo; c) as convergências e as divergências entre os autores diante de suas percepções sobre a produção bibliográfica, nos prognósticos e nos sentidos nas noções de recepção e circulação das ideias, presentes nos livros coletâneas da área ${ }^{19}$.

Após contextualizar obras e autores, apresentou-se no quarto e último capítulo, a sistematização analítica e crítica do debate. A análise tem como ponto de partida os conteúdos temáticos ${ }^{20}$ das obras. Consta que, numa perspectiva mannheimiana, essa avaliação também considera o conjunto dos condicionamentos sociais, estruturais, institucionais e políticos pelas quais essas obras são produzidas e sua relação com os processos de expansão e criação de novos de Licenciatura em Ciências Sociais no país. Além de, abordar os interpostos à formação de professores e à nova geração de jovens e adolescentes nas escolas no contexto atual. $\mathrm{O}$ exercício de avaliação das obras opera sobre as dimensões da linguagem sociológica e educacional, suas contribuições teórico-epistemológicas das agendas temáticas em uso na recepção e circulação das ideias e do constructo das tipologias de conhecimento em tela ${ }^{21}$. Ademais, destacam-se as projeções dos estudos enquanto perspectivas, possibilidades e limites revelados no intuito de avaliar em profundidade as obras.

Assim, em síntese, a abordagem exposta se remete aos Livros Coletâneas e ao ensino de Sociologia/Ciências Sociais na Educação Básica. A proposta, no seu conjunto discursivo, atendeu à intenção de elucidar as condições de produção dos sujeitos autores das obras dispostas nesta análise, além de contextualizá-las à dimensão histórica em que estão inseridas.

Apesar da abrangência da investigação e da tese, apresentamos uma síntese das principais considerações conclusivas. As agendas temáticas presentes nos livros coletâneas são um reflexo direto das práticas interlocutivas que, resumidas, apresentam-se em duas orientações específicas contexto e experiência - como lugar de criação, problematização, prática, diagnóstico e intervenção, ingredientes que retroalimentam as práticas e as teorizações, em que o debate poderá orientar novas

19 Essa discussão específica da tese em torno da Sociologia dos sociólogos que escrevem sobre o Ensino de Sociologia na Educação Básica e suas trajetórias está disponível no seguinte artigo: ERAS, Lígia Wilhelms. Trajetórias, travessias e produtores: sociologias, conhecimentos e os autores dos livros coletâneas sobre o Ensino de Sociologia na Educação Básica: In: Revista Brasileira de Sociologia. V. 2. Nº 3, 2014.

20 Esclareço que não é o uso da análise de discursos aos moldes que são aplicados no campo da análise da linguagem, o que exigiria novos redimensionamentos e condução metodológica e analítica de pesquisa,e sim, uma análise orientada para a uma perspectiva sociológica e temática de realização.

21 Essas discussões foram delineadas no paper: ERAS, Lígia Wilhelms. Produção de Conhecimento e Ensino de Sociologia na Educação Básica: a configuração do debate acadêmico-escolar nos livros coletâneas. XVII Congresso Brasileiro de Sociologia. GT Ensino de Sociologia. Porto Alegre: UFRGS, 2015. Disponível em: http://automacaodeeventos.com.br/sociologia2015/sis/inscricao/resumos/0001/R2485-1.PDF Acesso setembro de 2015. 
agendas de discussão. Demonstra que é um momento muito oportuno de valorização desses espaços, que é ao mesmo tempo lúdico e teórico.

No conjunto de uma avaliação crítica quanto aos avanços que representam essas produções, temos: a) a repercussão do trabalho desenvolvido em novos espaços e desenhos institucionais, especialmente localizados na formação de professores em Ciências Sociais; b) a produção de conhecimento escolar que se coaduna com um letramento sociológico científico; c) a presença dos Programas Institucionais de Bolsa de Iniciação a Docência em suas autorias; d) a ênfase do lugar da experiência nas produções; e) enfim, o processo de constituição das próprias obras em si, naquilo que permite fertilizar, condensar e desafiar o próprio debate.

Já num olhar crítico lacunar, peca-se pela ausência de aprofundamento: a) quanto a outros processos de aprendizagens (neurociência, psicologia, pedagogia); b) da reflexão sobre a ludicidade das práticas de ensino; c) da incorporação de novas linguagens a esfera de reflexão sobre o ensino; d) a baixa tiragem de livros coletâneas editados $(300,500,1000)$ e a não digitalização e, $\log$, dificuldades para a acessibilidade das obras; e) a não uniformidade de representação regional/nacional e institucional, predominando produções do Sul e do Sudeste do país.

As obras coletâneas registram a contribuição de inúmeros atores sociais que expressaram nas 'letras vivas' dos livros coletâneas uma longa história da educação - que entre avanços e novos rumos - imprimem uma história de luta pelo (re)conhecimento do Ensino de Sociologia na Educação Básica na agenda de debates das escolas e das universidades. Discussões que emendarão uma renovada escrita e a elaboração de novos capítulos no seu devir histórico.

\section{REFERÊNCIAS BIBLIOGRÁFICAS}

BALTAR, R.; BALTAR, C. S. A defasagem das ciências sociais no uso de recursos de informática para o ensino e a pesquisa no Brasil. La Educación - Revista Digital (OEA), v. 144, p. 2, 2010.

BOURDIEU, Pierre. A economia das trocas simbólicas. São Paulo: Editora Perspectiva, 2001. Paulo, 1998.

A economia as trocas lingüísticas. São Paulo: Editora da Universidade de São

As regras da arte. São Paulo: Companhia das Letras, 1996.

O poder simbólico. Rio de Janeiro: Bertrand Brasil, 1998. 
Os usos sociais da ciência: por uma sociologia clínica do campo científico. São Paulo: Editora UNESP, 2004.

BRASIL. Legislação Brasileira sobre educação. Brasília: Câmara dos Deputados, edições câmara, 2009.

BURKE, Peter. Sociologias e História do Conhecimento. In: Uma história social do conhecimento.De Gutenberg a Diderot. Rio de Janeiro: Zahar, 2003.

DWYER, Tom. As tecnologias de informação: morte ou vida para as ciências humanas? Sociologias,Porto Alegre, n. 12, Dec. 2004.

ERAS, Lígia Wilhelms. Trajetórias, travessias e produtores: sociologias, conhecimentos e os autores dos livros coletâneas sobre o Ensino de Sociologia na Educação Básica: In: Revista Brasileira de Sociologia. V. 2. No 3, 2014.

ERAS, Lígia Wilhelms. Produção de Conhecimento e Ensino de Sociologia na Educação Básica: a configuração do debate acadêmico-escolar nos livros coletâneas. XVII Congresso Brasileiro de Sociologia. GT Ensino de Sociologia. Porto Alegre: UFRGS, 2015. Disponível em: http://automacaodeeventos.com.br/sociologia2015/sis/inscricao/resumos/0001/R2485-1.PDF Acesso setembro de 2015.

FARIAS, L; VARGAS, A; BORGES, E. Um sistema para análise de redes de pesquisas baseado na plataforma Lattes. Revista Eletrônica de Sistemas da informação. Volume 10, 2006. Disponível e:http://paginas.ucpel.tche.br. Acesso em abril de 2014.

GUELFI, Wanirley. "A Sociologia como disciplina escolar no ensino secundário brasileiro: 1925-1942”. Dissertação de Mestrado, Curitiba, UFPR, 2001.

HOBSBAWM, Eric J. Sobre História: ensaios. SP: Cia das Letras, 1998.

JAMIL CURY, Carlos Roberto. A educação básica como direito.São Paulo: Cadernos de Pesquisa.Vol. 38, $\mathrm{n}^{\circ}$ 134, 2008.

KOSELLECK, Reinhart. Futuro passado: contribuição à semântica dos tempos históricos. Rio de Janeiro: Contraponto; PUC, 2006.

MANNHEIM, Karl. Sociologia da Cultura. São Paulo: Perspectiva, 1974.

Sociologia do Conhecimento. Rio de Janeiro: Zahar Editores, 1974.

NUNES, Patrícia. Alfabetização científico-tecnológico-digital e a Plataforma Lattes: quais sentidos? Dissertação de Mestrado em Educação. Programa de Pós-Graduação de Educação. São Leopoldo-RS: UNISINOS, 2006.

OLIVEIRA, Ricardo Costa. A Universidade que a genealogia paranaense criou em 1912. In: LEITE, Renato Lopes; OLIVEIRA, Ricardo Costa. Reflexões UFPR 100 anos. Curitiba: Editora UFPR, 2012. 
OLIVEIRA, Ricardo Costa. Na teia do nepotismo: Sociologia Política das relações de parentesco e poder político no Paraná e no Brasil. Curitiba: Insigth, 2012.

PULICI, Carolina. Entre sociólogos: versões conflitivas da “condição de sociólogo" na USP dos anos 1950-1960. São Paulo: Editora da Universidade de São Paulo/Fapesp, 2008.

RUBIM, Christina de Rezende. Antropólogos brasileiros e a Antropologia no Brasil: a era da pósgraduação. Tese de Doutorado em Antropologia Social. Instituto de Filosofia e Ciências Humanas. Universidade Estadual de Campinas (UNICAMP). 1996.

SANTOS, José Vicente Tavares dos. As Metodologias Informacionais: um novo padrão de trabalho científico para as Sociologias do Século XXI?. Sociologias. Porto Alegre, n.5, June 2001.

SILVA, Ileizi. "Das fronteiras entre a ciência e educação escolar as configurações do ensino de ciências sociais - sociologia no Estado do Paraná. 1970-2002”. Tese de Doutorado, USP, 2006.

SPIRANDELLI, Claudinei Carlos. Trajetórias Intelectuais: professoras do Curso de Ciências Sociais da FFCL-USP (1934-1969). Tese de Doutorado em Sociologia.São Paulo: Universidade de São Paulo, 2008.

STONE, Lawrence. Prosopografia. Tradução: LACERDA, Gustavo Biscaia; PERISSINOTTO, Renato Monseff. Revista Sociologia \&Política. Curitiba: UFPR, 2011. Volume 19, n³9, junho/2011.

VILLAS BÔAS, Glaucia. A vocação das ciências sociais no Brasil: um estudo da sua produção em livros do acervo da Biblioteca Nacional - Rio de Janeiro: Fundação Biblioteca Nacional, 2007.

\section{LIVROS COLETÂNEAS SOBRE O ENSINO DE SOCIOLOGIA (2004-2013)}

BRIDI, Maria Aparecida; ARAÚJO, Sílvia Maria; MOTIM, Benilde Lenzi. Ensinar e aprender Sociologia. São Paulo: Contexto, 2010.

CAINELLI, Marlene Rosa; SILVA, Ileizi Fiorelli (org.). O estágio na licenciatura: a formação de professores e a experiência interdisciplinar na Universidade Estadual de Londrina. Londrina: UEL, 2009.

CARVAlHO, Cesar Augusto (org.). A Sociologia no Ensino Médio (org.) - Londrina: EDUEL, 2010.

CARVALHO, Lejeune Mato Grosso (org.). Sociologia e ensino em debate: experiências e discussão de sociologia no ensino médio. Ijuí: Ed. Unijuí, 2004.

COLOGNESE, Silvio Antônio (org.). Fronteiras do saber sociológico. Porto Alegre: Evangraf, 2012. 
FIGUEIRO, André Videira; OLIVEIRA, Luiz Fernandes; PINTO, Nalayane Mendonça (orgs.). Sociologia na sala de aula: reflexões e experiências docentes no Estado do Rio de Janeiro. Rio de Janeiro: Imperial Novo Milênio, 2012.

FERREIRA, Lúcia de Fátima Guerra (org.). Subsídios para a educação em direitos humanos nas ciências sociais. João Pessoa: Editora Universidade da UFPB, 2010.

GONÇALVES, Danyelle Nilin (org.). Sociologia e Juventude no Ensino Médio: formação, PIBID e outras experiências. Pontes Editores: Campinas, 2013.

HANDFAS, Anita. OLIVEIRA, Luiz Fernandes (orgs.). A Sociologia vai à escola - Rio de Janeiro: Quartet FAPERJ, 2009.

HANDFAS, Anita; MAÇAIRA, Júlia Polessa (orgs.). Dilemas e perspectivas da Sociologia na Educação Básica. Rio de Janeiro: E-papers: 2012.

LIMA, Ângela Maria de Sousa (org.) As persistentes desigualdades brasileiras como temas para o Ensino Médio. Londrina: Eduel, 2011.

LIMA, Angela Maria de Sousa; ARAÚJO, Angélica Lyra; FERREIRA, Jaqueline; MOTTA, Sílvia Conceição Longuin (orgs.). Sugestões didáticas de Ensino de Sociologia. Londrina: UEL, 2012.

LIMA, Angela Maria Sousa, VITALIANO, Célia Regina, ALTIANO, Fabiane Cristina, MACHADO, Rosemeri Passos Baltazar (orgs). Inclusão: debates em diferentes contextos. Londrina: EDUEL, 2013.

LIMA, Angela Maria Sousa, ARAÚJO, Angélica Lyra; LIMA, Alexandre Jerônimo Correia; FERREIRA, Adriana Fátima; CARVALHO, Cézar Augusto; SILVA, Ileizi Luciana Fiorelli; SCHEVIBISKI, Renata Schlumberger; SILVEIRA, Ricardo de Jesus (orgs.). Práticas e Debates na formação de professores de Sociologia/Ciências Sociais. Londrina: EDUEL, 2013.

MEIRELLES, Mauro; RAIZER, Leandro; PEREIRA, Luiza Helena (orgs). O ensino de sociologia no RS: repensando o lugar da sociologia. Porto Alegre: Evangraf/LAVIECS, 2013.

MORAES, Amaury César (org.). Coleção Explorando o Ensino. Sociologia. Volume 15. Ministério da Educação, Secretaria de Educação Básica, 2010.

OLIVEIRA, Dijaci David; RABELO, Danilo; FREITAS, Revalino Antônio (orgs). Sociologia no Ensino Médio: experiências e desafios. Goiânia: UFC/FUNAPE, 2010.

Ensino de Sociologia: currículo, metodologia e formação de professores. Goiânia: UFG/FUNAPE, 2011.

OLIVEIRA, Dijaci David; FREITAS, Revalino Antônio; TOSTA, Tânia Ludmila Dias (orgs.). Sociologia e Educação em direitos humanos. Goiânia: UFG/FUNAPE, 2010.

OLIVEIRA, Luiz Fernandes, André Videira, Nalayane Pinto (orgs). Sociologia na sala de aula: reflexões e experiências docentes no Estado do Rio de Janeiro. Rio de Janeiro: Imperial Novo Milênio, 2012. 
OLIVEIRA, Luiz Fernandes (org.). Ensino de Sociologia: desafios teóricos e pedagógicos para a s Ciências Sociais. Seropédica-RJ: Editora da UFRRJ, 2013.

OLIVEIRA, Márcio de (org.). As Ciências Sociais no Paraná. Curitiba: Protexto, 2006.

PLANCHEREL, Alice Anabuki. OLIVEIRA, Evelina Antunes F. (orgs.) Leituras sobre sociologia no Ensino Médio. Maceió: EDUFAL, 2007.

RAMALHO, José Rodorval. SOUZA, Rozenval de Almeida (org.). Pibid: Memórias de iniciação à docência - Campina Grande: Editora da UFCG, 2013.

SANTOS, Adriana Regina de Jesus (orgs). Práticas e reflexões de ensino e pesquisa do projeto PRODOCÊNCIA da UEL. Londrina: Universidade Estadual de Londrina, 2012.

SILVA, Ileizi Luciana Fiorelli (orgs.) Cadernos de metodologias de ensino e pesquisa de sociologia: Lenpes laboratório de ensino, pesquisa e extensão de sociologia. Curitiba: SETI-PR, 2009.

SOUSA, Fernando Ponte (org.). Sociologia conhecimento e ensino. Florianópolis: Editora em Debate, 2012.

\title{
RESEARCH WITH BOOKS AND COLLECTIONS AND SOCIOLOGY TEACHING IN BASIC EDUCATION: COURSES AND EXPERIENCES
}

\begin{abstract}
The feature article describes the route and the research methods and the dense experience, challenges and reasons to employ the reflection of efforts whose main object of the research focused on the conditions of production of the collections books on the sociology of education in basic education, materialized into space and the format of books collections.
\end{abstract}

Keywords: Sociology of Education; Books Compilation: Research Methodologies; Trajectories. 